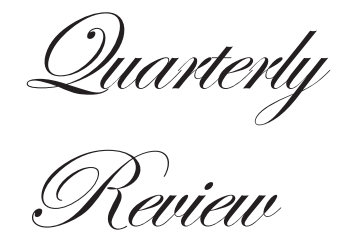

Department of Gastroenterology,
Postgraduate Institute of Medical
Education and Research,
Chandigarh - 160012, India
Correspondence:
Dr. DeepakKBhasin
Email: $\underline{\text { deepakkbhasin@ gmail.com }}$

\section{Medical management of pain in chronic pancreatitis}

\author{
Vishal Sharma, Surinder Singh Rana, Deepak Kumar Bhasin
}

ABSTRACT

\begin{abstract}
Chronic pancreatitis is a common disorder caused by various etiological factors. It usually manifests with abdominal pain and exocrine (steatorrhea, malnutrition) or endocrine insufficiency (diabetes mellitus). Abdominal pain is the dominant symptom in these patients. Medical, endoscopic and surgical modalities are available for therapy. This review focuses on the pharmacological approaches to manage pancreatitis pain. Before embarking on medical management of pain it is prudent to exclude complications like pancreatic cancer, pseudocysts, inflammatory mass, biliary or duodenal obstruction which may contribute to abdominal pain. Pharmacological measures for pain relief include central analgesics, enzyme supplements and antioxidants. Other measures include endoscopic and surgical therapy which are not discussed here. Appropriate management of exocrine and endocrine insufficiency and successful control of diabetes are also important in the management of chronic pancreatitis.
\end{abstract}

KEYWORDS: Pancreatitis, alcohol abstinence, tramadol, pregabalin, pancreatic enzyme replacement, antioxidants

\title{
Introduction
}

Chronic pancreatitis (CP) is a fibro-inflammatory disorder of the pancreas characterised by progressive and irreversible damage. It manifests with abdominal pain and/or exocrine or endocrine insufficiency. ${ }^{1}$ It is the end result of many etiological factors which cause pancreatic injury. The diagnosis of $\mathrm{CP}$ should be entertained only in an appropriate clinical setting because the histological findings of CP (chronic inflammation, fibrosis and glandular destruction) can accompany many conditions like chronic alcohol abuse, old age, diabetes mellitus and chronic kidney disease. ${ }^{2}$ The TIGARO classification provides an etiological approach to classify chronic pancreatitis. The classification lists various etiological agents/ processes implicated in the causation of chronic pancreatitis and includes: Toxic-metabolic (alcohol, tobacco, toxins, hypercalcemia, chronic kidney disease), Idiopathic (early or late onset), Genetic (hereditary due to mutations in cationic trypsinogen, CFTR or SPINK-1), Autoimmune (associated with systemic sclerosis, IgG4 related sclerosing disease), Recurrent (as a result of recurrent episodes of acute pancreatitis) or Obstructive (pancreas divisum, pancreatic malignancy or intraductal mucinous neoplasm). ${ }^{1,3,4}$ However, clinicians commonly use a classification system based on changes in the main pancreatic duct. Small duct disease is characterised by a pancreatic duct diameter of $<5 \mathrm{~mm}$ or minimal ductal changes; while in large duct disease the main pancreatic duct is dilated ( $>5 \mathrm{~mm}$ ) and there are demonstrable abnormalities on ERCP or MRCP. ${ }^{5}$ The diagnosis of small duct pancreatitis is usually based on presence of typical pain and changes of chronic pancreatitis on endoscopic ultrasound although abnormalities on direct hormonal stimulation tests in wake of normal ERCP remains the standard for diagnosis. ${ }^{6}$ The distinction into small and large duct disease has important therapeutic implications as will be discussed subsequently. The management of chronic pancreatitis is multidimensional: management of underlying 
etiology, management of abdominal pain and management of exocrine and endocrine insufficiency, malnutrition and complications like pseudocyst, pseudoaneurysm, biliary obstruction or pancreatic cancer. The present review will focus on the medical management of pain in chronic pancreatitis.

\section{Approach to management of chronic pancreatitis}

Before embarking on the management of chronic pancreatitis, it is important to arrive at a correct diagnosis, clarify the underlying etiology or risk factors and correct them, followed by management of symptoms especially abdominal pain and/ or endocrine or exocrine insufficiency. The diagnosis is often established by history, imaging modalities like abdominal ultrasound, computed tomography (CT), magnetic resonance pancreatography (MRCP), endoscopic ultrasound (EUS) or occasionally endoscopic retrograde pancreaticography (ERCP). ${ }^{3-5}$ While these modalities are excellent for diagnosing large duct disease, small duct disease may escape detection because these modalities primarily focus on ductal changes. In such situations, endoscopic ultrasound can be utilised to look at the parenchymal changes which can help in the diagnosis of chronic pancreatitis in the absence of ductal changes. ${ }^{7,8}$ Although various functional tests have been described their use is uncommon in clinics and they are primarily utilised in research/investigational settings. Once a definite diagnosis of chronic pancreatitis has been established it is important to be aware of all the problems which the patient may have. It is useful to evaluate the abdominal pain which is the most common and the dominating symptom in these patients. An evaluation for exocrine and endocrine functions must also be done. ${ }^{9}$ The evaluation must include efforts to clearly delineate the anatomy of the pancreatic duct vis-à-vis the presence of ductal dilatation, stricture, disruption and ductal calculi. MRCP provides a good modality for detecting these abnormalities. The evaluation is incomplete without an evaluation of associated complications. Often the cause of underlying pain will be presence of a pseudocyst, pancreatic head mass (inflammatory or malignant) or biliary obstruction. These complications will need appropriate endoscopic and/or surgical therapy and may alleviate patient's symptoms.

\section{Management of etiology and risk factors}

Various etiological factors responsible for $\mathrm{CP}$ have already been described. The most common etiologies are idiopathic and alcohol. ${ }^{10}$ Recently, tobacco has also been recognised as a risk factor. A meta-analysis of 12 studies indicated that current smokers had a 2.8 times higher relative risk for occurrence of chronic pancreatitis vis-à-vis non-smokers after adjustment for alcohol intake. ${ }^{11}$ Tobacco accelerates the progression of alcohol related chronic pancreatitis and exhibits a dose response relationship with the onset of pancreatic exocrine insufficiency (PEI) and occurrence of pancreatic calcifications. With increasing pack-years of tobacco smoking, the diagnosis of chronic pancreatitis was made earlier and with further increases the likelihood of detection of pancreatic calcifications and presence of PEI increased. ${ }^{12}$ Another recent report has also implicated smoking as a factor in progression of CP into complications like calcifications and PEI but not with diabetes mellitus. ${ }^{13}$ In a large population based study on acute pancreatitis examining the effect of smoking cessation, smoking was reported as a risk factor for non-gallstone pancreatitis but the risk reduced to non-smoker levels two decades after cessation of smoking. ${ }^{14}$ Also, in a report on 360 patients of chronic pancreatitis who were followed up for more than 6 years, the odds of developing pancreatic calcification increased with increasing levels of smoking and smoking cessation reduced the risk of calcification to levels similar in nonsmokers. ${ }^{15}$

There is evidence to support abstinence from alcohol as an important intervention in management of CP. In a report on 50 patients with alcohol related CP, Strum and colleagues followed 42 patients for a period from 1-13 years and demonstrated that 17 out of the 21 patients who had resumed normal life had stopped alcohol intake. Of the 21 who suffered complications of $\mathrm{CP}$, eight patients had continued to take alcohol. The effect on abdominal pain was also apparent. Of 18 patients who stopped alcohol 12 had no pain while out of the seven patients who continued to drink, only one was pain-free. ${ }^{16}$ There are multiple other reports which demonstrate the benefit of alcohol abstinence in alleviation of abdominal pain in patients with alcohol related pancreatitis. ${ }^{17,18}$ A pancreatographic study also demonstrated stabilisation of ductal changes of pancreatitis in individuals who abstained from alcohol. ${ }^{19}$ A randomised study which evaluated the role of repeated interventions every six months by nurses against alcohol intake in a group of patients with alcohol related acute pancreatitis, reduction in the incidence of recurrent pancreatitis in the intervention group was noted suggesting a role for repeated emphasis on abstinence to prevent pancreatic pain. ${ }^{20}$ The implication of etiology management has also been reported in relation to 
hyperparathyroidism related pancreatitis. In a report examining primary hyperparathyroidism related chronic pancreatitis in nine patients, six underwent parathyroidectomy. These were followed up for $14.3 \pm 13.8$ months (6-36 months) and none of them suffered a recurrence of abdominal pain suggesting a benefit from treatment of underlying etiology in alleviating abdominal pain..$^{21}$

\section{Management of abdominal pain}

Analgesics

Abdominal pain is the most dominant symptom of chronic pancreatitis. It is now understood that the genesis of pain in CP involves both local pancreatic ductal and parenchymal changes, as also changes in pain perception at peripheral and central level. Some authors have described these as problems with plumbing and wiring respectively. ${ }^{22,23}$ Figure 1 depicts the various factors which may be responsible for pain in chronic pancreatitis and the directed management of various factors. ${ }^{6,22,24}$ The role of analgesics is important and most patients with $\mathrm{CP}$ will require some form of analgesia. ${ }^{25}$ The use of analgesics has to be tempered by the possible risk of addiction associated with use of opioids and other side effects associated with indiscriminate use of nonsteroidal antiinflammatory drugs (NSAIDS). ${ }^{26}$ The risk of opioid dependence may be more in alcohol abusers. In a report on 219 patients with $\mathrm{CP}$, around half of the patients needed opioids for analgesia. ${ }^{27}$ Before embarking on medical therapy it is important to fully evaluate the nature and consequences of the pain: is it episodic or continuous, what is the frequency, are there any aggravators, and does it impact sleep or work? It may also be worthwhile to assess the patients for depression as presence of affective disorders correlates with pain severity. ${ }^{27}$ In a report assessing opioid misuse in 307 patients with non-alcoholic chronic pancreatitis, the presence of depressive symptoms and alcohol use seemed to increase the risk of opioid misuse. ${ }^{28}$ While episodic pain can be managed with SOS analgesics, chronic pain would need some ongoing medication as well as SOS medications for exacerbations.

Only few studies have evaluated the efficacy of various analgesics used for pain management in CP. In a small, crossover randomised study of 18 patients comparing transdermal fentanyl patch with sustained release morphine, no difference in efficacy vis-à-vis pain relief or quality of life was seen. However, there was a need to give a higher dose of fentanyl than recommended by the manufacturer, there were more cutaneous side effects and a need for daily administration of a higher immediate release morphine for pain relief. Even with these caveats, the study suggests that transdermal fentanyl patches may be valuable for the management of abdominal pain in $\mathrm{CP}^{29}$ Tramadol has emerged as an important drug for management of pancreatic pain with actions directed both at the opioid receptors as well as serotonin-norepinephrine reuptake inhibition and has a lesser abuse potential. In a double blinded randomised trial on 25 patients comparing oral morphine against tramadol given for a duration of 5 days, more patients on tramadol reported their analgesia to be better than morphine at day 4. Patients on morphine suffered an increase in orocaecal and colonic transit time suggesting a greater effect of morphine on gastrointestinal function. The mean dose for tramadol and morphine over four days was $840 \mathrm{mg}$ and $238 \mathrm{mg}$, respectively. ${ }^{30}$ Fixed drug combinations of tramadol with

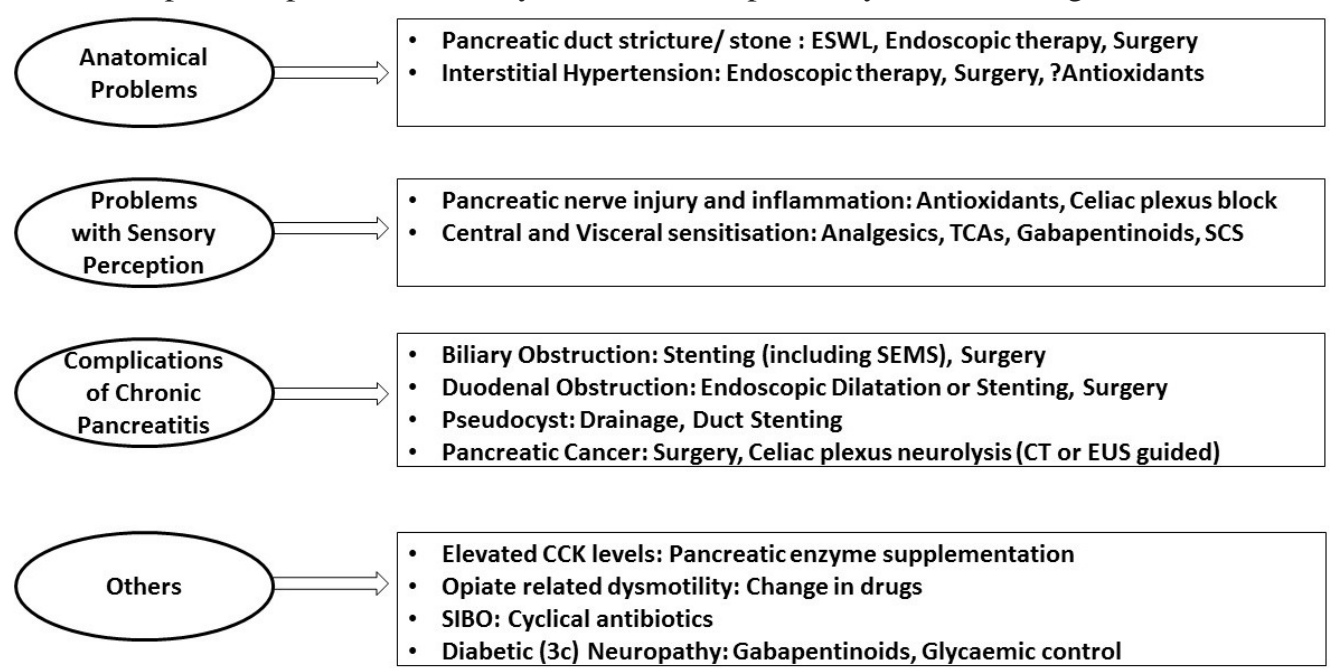

Figure 1: Mechanisms of pain in chronic pancreatitis and their management. (ESWL: extracorporeal shock wave lithotripsy; TCAs: tricyclic antidepressants; SCS: spinal cord stimulation; SEMS: self expanding metallic stent; CCK: cholecystokinin; SIBO: small intestinal bacterial overgrowth) 
Table 1: Various medications used in management of pain in chronic pancreatitis

\begin{tabular}{|c|c|c|}
\hline Dosage & Side-effects or Precautions & \\
\hline \multicolumn{3}{|l|}{ Analgesics } \\
\hline Acetaminophen & $\begin{array}{l}\text { Daily dosage: Not to exceed } 4 \mathrm{gm} / \mathrm{d} \text { 325-650 mg } \\
\text { every 4-6 hourly }\end{array}$ & Dyspepsia, Hepatotoxicity, Gastrointestinal bleed \\
\hline Tramadol & $\begin{array}{l}\text { Start: } 50-100 \mathrm{mg} / \text { dayIncrease: } 50-100 \mathrm{mg} / \text { day } \\
\text { every 3-7 daysMaximum: } 400 \mathrm{mg} / \mathrm{d}\end{array}$ & Constipation, dizziness, headache, Somnolence \\
\hline Morphine & $\begin{array}{l}\text { Acute Pain: } 15-30 \mathrm{mg} \text { every } 4 \text { hourly } \\
\text { Maximum: } 120-180 \mathrm{mg} / \mathrm{d}\end{array}$ & $\begin{array}{l}\text { Pruritus, Urinary retention, constipation, addiction } \\
\text { potential, respiratory depression }\end{array}$ \\
\hline \multicolumn{3}{|l|}{$\underline{\text { Central Analgesics }}$} \\
\hline Amitriptyline & $\begin{array}{l}\text { Start: } 10-25 \mathrm{mg} \text { HSIncrease: } 10-25 \mathrm{mg} \text { per week } \\
\text { Maximum: } 300 \mathrm{mg} / \mathrm{d}\end{array}$ & $\begin{array}{l}\text { Blurred vision, confusion, dry mouth, orthostatic } \\
\text { hypotension, urinary retention }\end{array}$ \\
\hline Pregabalin & $\begin{array}{l}\text { Start: } 75 \mathrm{mg} \text { BDIncrease: } 150 \mathrm{mg} / \mathrm{d} \text { every } 3-7 \text { days } \\
\text { Maximum: } 600 \mathrm{mg}\end{array}$ & $\begin{array}{l}\text { Dizziness, somnolence, peripheral edema, } \\
\text { xerostomia }\end{array}$ \\
\hline \multicolumn{3}{|l|}{ Antioxidants } \\
\hline $\begin{array}{l}\text { Vitamin A, C, E, } \\
\text { Selenium, Methionine }\end{array}$ & $\begin{array}{l}\text { As used in trials ( } 600 \mathrm{mcg} \text { organic selenium, } 0.54 \mathrm{~g} \\
\text { ascorbic acid, } 9000 \mathrm{IU} \text { beta-carotene, } 270 \mathrm{IU} \\
\text { alpha-tocopherol and } 2 \mathrm{~g} \text { methionine) }\end{array}$ & Not mentioned \\
\hline \multicolumn{3}{|l|}{ Pancreatic Enzymes } \\
\hline $\begin{array}{l}\text { Non-enteric coated } \\
\text { preparation }\end{array}$ & $\begin{array}{l}64000 \text { USP with each meal and co-treatment with } \\
\text { PPI/H2 blocker }\end{array}$ & $\begin{array}{l}\text { Abdominal cramping, Headache, Fibrosing colopathy } \\
\text { (children, high dosage, enteric coated) }\end{array}$ \\
\hline
\end{tabular}

acetaminophen are also available and can be used in CP.

The 'wiring' problems including neuronal damage causing sensitisation of peripheral nerve endings and changes in the central nervous system especially the cortical centres, require central analgesics for the management of chronic pancreatitis refractory pain. Allodynia and hyperalgesia are both common phenomenon in $\mathrm{CP} .{ }^{31}$ Also the level of central sensitization may vary with the stage of chronic pancreatitis. ${ }^{32}$ Therefore drugs like tricyclic antidepressants (TCAs) and gabapentinoids have a role in pain control in patients with CP. Amitriptyline is commonly used for analgesia in these patients. TCAs work synergistically with opioids and also help tackle concomitant depression. ${ }^{33}$ Gabapentinoids act by reducing the release of excitatory neurotransmitters like glutamate, calcitonin gene related peptide and substance $\mathrm{P}$ which have a role in genesis of pain. Of the two gabapentinoids in clinical use, pregabalin has got a better potency for analgesia, higher oral bioavailability and longer duration of action than gabapentin. ${ }^{34}$ The use of pregabalin has been evaluated in pancreatic pain. In a randomised double blinded placebo controlled trial evaluating the use of pregabalin in 64 patients with chronic pancreatitis for a duration of three weeks, Olesen et al demonstrated that pregabalin was more effective in achieving pain relief as measured by visual analogue scale. Also, patients on pregabalin had a better perception of their health status whilst the two groups had a similar quality of life and adverse event profile. ${ }^{35}$ The same group also demonstrated that the success of therapy with pregabalin can be predicted with the use of electrical pain detection ratio and the responder had an increased sensitivity to the electric tetanic stimulation of the pancreatic area than non-responders. Quantitative sensory testing involves use of different external stimuli to evaluate peripheral and central sensory function. ${ }^{36}$ Also the effectiveness of pregabalin in pain relief is commensurate with changes in electroencephalographic features including slowing of brain wave oscillations as recorded by changes in spectral patterns of electroencephalography. An increase in theta wave activity was noted with pregabalin treatment. ${ }^{37}$ These reports suggest that personalised analgesic therapy by use of sensory testing to predict response to a particular pharmacological agent may become a reality for the patients with chronic pancreatitis in the future. The dosage and side-effects of commonly used pharmacological therapies for pancreatic pain is summarised in Table 1. 6,22,24 Although some authors have suggested that the WHO ladder of pain relief recommended for cancer pain may be as useful for pain in $\mathrm{CP}$, the use of opioids must be tempered with caution to avoid potential abuse.

\section{Pancreatic enzymes supplementation}

It is believed that changes in ductal architecture are partly responsible for occurrence of pain in CP. Such ductal changes especially presence of stone or strictures may cause obstruction to the free flow of pancreatic enzymes upon dietary stimulation. Indeed aggravation of pain with meals and resultant fear of eating (sitophobia) is a common feature of pancreatic pain. ${ }^{38}$ 
Therefore it is hypothesised that inhibition of meal related pancreatic secretion may help in pain management. Delivery of pancreatic enzymes (especially proteases) destroys the intestinal CCK releasing factor thereby overcoming the hyperstimulatory state that exists in $\mathrm{CP} .{ }^{33,39}$ To ensure efficacy of enzymes in management of pain, the duodenal delivery of pancreatic enzymes has to be ensured and therefore the use of uncoated (non-enteric coated or tablet) preparations may be of value to achieve this clinical end. Also since pancreatic secretions are only partly under humoral control the benefits are only marginal. Trials showing benefit from pancreatic enzymes had used non-enteric coated preparations in high daily dosage of 192,000 USP of lipase (64,000 USP of lipase with meals and at night). ${ }^{39,40}$ It is also prudent to use proton pump inhibitors concomitantly to avoid degradation by acid in the stomach. The benefit is most apparent in patients with small duct disease. Multiple other trials have demonstrated no benefit of enteric coated enzyme preparations at similar or even higher doses. ${ }^{41-44}$ These trials have used enzymes for varying periods ranging from 3 weeks to 4 months. ${ }^{35-40}$ This highlights that is important to use the enzymes in patients who are more likely to benefit from their administration. A report evaluating the use of non-enteric coated pancreatic enzymes in a group of patients with pancreatic abdominal pain suggested that the response was better in those with endoscopic ultrasound features consistent or suggestive of $\mathrm{CP}$ as per the Rosemunt criteria. $^{45}$

\section{Antioxidants}

One of the theories explaining the pathogenesis of $\mathrm{CP}$ is the electrophilic stress theory, which implicates toxic metabolites and glutathione depletion as one of the mechanisms leading to inflammation and fibrosis. Thus, the correction of oxidantantioxidant balance may halt the inflammation and provide pain relief. ${ }^{1,46}$ Multiple clinical trials have evaluated the use of antioxidants for treating chronic pancreatitis pain. In a randomised trial the investigators randomised patients with $\mathrm{CP}$ to either placebo or an antioxidant combination (600 ìg organic selenium, $0.54 \mathrm{~g}$ ascorbic acid, $9000 \mathrm{IU}$ â-carotene, 270 IU á-tocopherol and $2 \mathrm{~g}$ methionine daily dose). The results indicated a significant reduction in number of monthly painful days and usage of analgesics in the antioxidant arm. The reduction in lipid peroxidation products (thiobarbituric acid reactive substances) was also higher in the antioxidant arm and the total antioxidant capacity (ferric reducing ability of plasma) was higher. Study dropouts were higher in the placebo arm $(21 \%)$ than in the treatment arm $(6.6 \%) .{ }^{47}$ However, the ANTICIPATE trial which randomised 70 patients to receive either placebo or 6 tablets/day of antioxidant combination (each tablet containing 50 ìg l-selenomethionine, $113.4 \mathrm{mg}$ of átocopherol acetate, $126.3 \mathrm{mg}$ ascorbic acid, $480 \mathrm{mg}$ l-methionine and $44.2 \mathrm{mg}$ â-carotene) for six months, noted no difference in average pain scores amongst the two groups. The intake of opiates was similar for the two groups in this trial. ${ }^{48}$ There were differences in these two trials. The former was conducted on an Indian population with idiopathic $\mathrm{CP}$ as the main etiology and mean patient age of $\sim 30$ years. The ANTICIPATE trial on the other hand, largely included alcoholic pancreatitis patients with a mean age of 50 years and a significant number of patients $(54 \%)$ had received prior intervention. There were differences in the dosage of the antioxidants used in these trials as well. ${ }^{47,48}$

Of note, multiple other reports have indicated benefit in pain with use of antioxidants. In a double blinded cross over trial of 20 patients with recurrent pancreatitis (15 having $\mathrm{CP}$ ), receiving antioxidants (vitamin $\mathrm{A}, \mathrm{C}, \mathrm{E}$, selenium and methionine), none of the patients suffered an attack of acute pain while on antioxidants. ${ }^{49}$ Another double blinded randomised cross over trial demonstrated benefits in pain relief and quality of life vis-à-vis the use of placebo. ${ }^{50}$ Another report on 61 patients with $\mathrm{CP}$, allocated to either placebo or antioxidants for 3 months noted that greater reduction in platelet derived growth factor AA (PDGF-AA) was in the antioxidant arm. The reduction in PDGF-AA correlated with reduction in pain and reduced need for analgesics. PDGF-AA is a marker of pancreatic fibrosis and increases stellate cell proliferation. ${ }^{51}$ However a systematic review suggested that use antioxidant combinations (vitamins A, C, E, selenium and methionine) were more likely to be beneficial for pain in chronic pancreatitis rather than use of a single drug. ${ }^{52}$ In single drug trials, use of Sadenosyl methionine, curcumin (active principle of turmeric), allopurinol and dimethyl sulfoxide (DMSO) has been reported. Most of these trials have not reported any benefit except for a trial involving rectal administration of allopurinol and DMSO. ${ }^{52-}$

${ }^{55}$ All in all, it seems that the modest benefits of combination antioxidants in relief of pain in chronic pancreatitis may be more pronounced in younger patients with non-alcoholic etiology, small duct disease and those who have not failed interventions for relief of abdominal pain.

\section{Other measures}

Octreotide, a somatostatin analogue, inhibits pancreatic secretions and has been evaluated for pain relief in chronic 
pancreatitis. The results have been contradictory. In a crossover trial use of subcutaneous octreotide for three days in ten patients with $\mathrm{CP}$, no significant benefit was noted in pain reduction. ${ }^{56}$ However, another report using octreotide thrice daily in six patients report some analgesic efficacy ${ }^{57}$ Another report on use of long acting octreotide (Octreotide-LAR) indicated that its efficacy was equivalent to short-acting octreotide in six patients with CP related pain. ${ }^{58}$ Electroacupuncture and transcutaneous electric nerve stimulation have also been evaluated and in 23 patients with $\mathrm{CP}$ and were found to be less effective than medical treatment. ${ }^{59}$ Efficacy of spinal cord stimulation has also been reported but the experience is limited. ${ }^{60,61}$ In a 12 week study using yoga for patients with chronic pancreatitis amongst 24 patients, a reduction in need for pain medication, reduced pain perception and anxiety were noted suggesting some benefits. ${ }^{62}$

\section{Beyond pain management}

Management of chronic pancreatitis must include management of exocrine insufficiency which is a late feature in the course of chronic pancreatitis and manifests as steatorrhea. Other complications like pancreatogenic diabetes, small intestinal bacterial overgrowth (SIBO), nutritional abnormalities like vitamin deficiency, gastroparesis and osteopenia and osteoporosis should be monitored and corrected. ${ }^{3,6,24} \mathrm{To}$ summarise, successful medical management of chronic pancreatitis encompasses evaluation and treatment of abdominal pain, exocrine and endocrine insufficiency and malnutrition. If abdominal pain cannot be controlled with medical therapies or if complications like pseudocyst, head mass, biliary or duodenal obstruction co-exist, it may be worthwhile to use invasive (endoscopic or surgical) therapies for optimal relief of symptoms.

\section{References}

1. Braganza JM, Lee SH, McCloy RF, McMahon MJ. Chronic pancreatitis. Lancet. 2011;377:1184-97.

2. Stamm BH. Incidence and diagnostic significance of minor pathologic changes in the adult pancreas at autopsy: a systematic study of 112 autopsies in patients without known pancreatic disease. Hum Pathol. 1984;15:677-83.

3. Etemad B, Whitcomb DC. Chronic pancreatitis: diagnosis, classification, and new genetic developments. Gastroenterology. 2001;120:682-707.

4. Stevens T, Conwell DL, Zuccaro G. Pathogenesis of chronic pancreatitis: an evidence-based review of past theories and recent developments. Am J Gastroenterol. 2004;99:2256-70.

5. Chaudhary V, Rana SS, Rao C, Bhasin DK. Management Strategies in Chronic Pancreatitis. In: Mediciane Update 2013 API India pp. 271-6.

6. Lieb JG, 2nd, Forsmark CE. Review article: pain and chronic pancreatitis. Aliment Pharmacol Ther. 2009;29:706-19.

7. Catalano MF, Sahai A, Levy M, Romagnuolo J, Wiersema M, Brugge W, et al. EUS-based criteria for the diagnosis of chronic pancreatitis: the Rosemont classification. Gastrointest Endosc. 2009; 69:1251-61.

8. Stevens T, Parsi MA. Endoscopic ultrasound for the diagnosis of chronic pancreatitis. World J Gastroenterol. 2010;16:2841-50.

9. Rickels MR, Bellin M, Toledo FG, Robertson RP, Andersen DK, Chari ST, et al. Detection, evaluation and treatment of diabetes mellitus in chronic pancreatitis: recommendations from PancreasFest 2012. Pancreatology. 2013;13:336-42.

10. Bhasin DK, Singh G, Rana SS, Chowdry SM, Shafiq N, Malhotra S, et al. Clinical profile of idiopathic chronic pancreatitis in North India. Clin Gastroenterol Hepatol. 2009;7:594-9.

11. Andriulli A, Botteri E, Almasio PL, Vantini I, Uomo G, Maisonneuve $\mathrm{P}$, et al. Smoking as a cofactor for causation of chronic pancreatitis: a meta-analysis. Pancreas. 2010;39:1205-10.

12. Rebours V, Vullierme MP, Hentic O, Maire F, Hammel P, Ruszniewski $\mathrm{P}$, et al. Smoking and the course of recurrent acute and chronic alcoholic pancreatitis: a dose-dependent relationship. Pancreas. 2012;41:1219-24.

13. Luaces-Regueira M, Iglesias-Garcia J, Lindkvist B, CastineiraAlvarino M, Nieto-Garcia L, Larino-Noia J, et al. Smoking as a risk factor for complications in chronic pancreatitis. Pancreas. 2014;43:275-80.

14. Sadr-Azodi O, Andren-Sandberg A, Orsini N, Wolk A. Cigarette smoking, smoking cessation and acute pancreatitis: a prospective population-based study. Gut. 2012;61:262-7.

15. Talamini G, Bassi C, Falconi M, Sartori N, Vaona B, Bovo P, et al. Smoking cessation at the clinical onset of chronic pancreatitis and risk of pancreatic calcifications. Pancreas. 2007;35:320-6.

16. Strum WB. Abstinence in alcoholic chronic pancreatitis. Effect on pain and outcome. J Clin Gastroenterol. 1995;20:37-41.

17. Hayakawa T, Kondo T, Shibata T, Sugimoto Y, Kitagawa M. Chronic alcoholism and evolution of pain and prognosis in chronic pancreatitis. Dig Dis Sci. 1989;34:33-8.

18. Gastard J, Joubaud F, Farbos T, Loussouarn J, Marion J, Pannier M, et al. Etiology and course of primary chronic pancreatitis in Western France. Digestion. 1973;9:416-28.

19. Maejima S, Kawa S, Hasebe O, Homma T. The relationship between drinking status and serial changes of pancreatographic findings in patients with suspected early chronic alcoholic pancreatitis. Pancreas. 1996;13:209-14.

20. Nordback I, Pelli H, Lappalainen-Lehto R, Jarvinen S, Raty S, Sand $\mathrm{J}$. The recurrence of acute alcohol-associated pancreatitis can be reduced: a randomized controlled trial. Gastroenterology. 2009;136:848-55.

21. Bhadada SK, Udawat HP, Bhansali A, Rana SS, Sinha SK, Bhasin DK. Chronic pancreatitis in primary hyperparathyroidism: comparison with alcoholic and idiopathic chronic pancreatitis. J Gastroenterol Hepatol. 2008;23:959-64.

22. Poulsen JL, Olesen SS, Malver LP, Frokjaer JB, Drewes AM. Pain and chronic pancreatitis: a complex interplay of multiple mechanisms. World J Gastroenterol. 2013;19:7282-91.

23. Anaparthy R, Pasricha PJ. Pain and chronic pancreatitis: is it the plumbing or the wiring? Curr Gastroenterol Rep. 2008;10:101-6.

24. Forsmark CE. Management of chronic pancreatitis. Gastroenterology. 2013;144:1282-91 e3.

25. Garg PK, Tandon RK. Survey on chronic pancreatitis in the Asia- 
Pacific region. J Gastroenterol Hepatol. 2004;19:998-1004.

26. Savage SR, Kirsh KL, Passik SD. Challenges in using opioids to treat pain in persons with substance use disorders. Addict Sci Clin Pract. 2008; 4:4-25.

27. Nusrat S, Yadav D, Bielefeldt K. Pain and opioid use in chronic pancreatitis. Pancreas. 2012;41:264-70.

28. Barth KS, Balliet W, Pelic CM, Madan A, Malcolm R, Adams D, et al. Screening for current opioid misuse and associated risk factors among patients with chronic nonalcoholic pancreatitis pain. Pain Med. 2014;15:1359-64.

29. Niemann T, Madsen LG, Larsen S, Thorsgaard N. Opioid treatment of painful chronic pancreatitis. Int J Pancreatol. 2000;27:235-40.

30. Wilder-Smith CH, Hill L, Osler W, O'Keefe S. Effect of tramadol and morphine on pain and gastrointestinal motor function in patients with chronic pancreatitis. Dig Dis Sci. 1999;44:1107-16.

31. Goulden MR. The pain of chronic pancreatitis: a persistent clinical challenge. Br J Pain. 2013;7:8-22.

32. Bouwense SA, Olesen SS, Drewes AM, Frokjaer JB, van Goor H, Wilder-Smith $\mathrm{OH}$. Is altered central pain processing related to disease stage in chronic pancreatitis patients with pain? An exploratory study. PLoS One. 2013;8:e55460.

33. Chauhan $\mathrm{S}$, Forsmark CE. Pain management in chronic pancreatitis: A treatment algorithm. Best Pract Res Clin Gastroenterol. 2010;24:323-35.

34. Ramaswamy S, Wilson JA, Colvin L. Non-opioid-based adjuvant analgesia in perioperative care. Contin Educ Anaesth Crit Care Pain. 2013;13:152-7.

35. Olesen SS, Bouwense SA, Wilder-Smith OH, van Goor H, Drewes AM. Pregabalin reduces pain in patients with chronic pancreatitis in a randomized, controlled trial. Gastroenterology. 2011;141:536-43.

36. Olesen SS, Graversen C, Bouwense SA, van Goor H, Wilder-Smith $\mathrm{OH}$, Drewes AM. Quantitative sensory testing predicts pregabalin efficacy in painful chronic pancreatitis. PLoS One. 2013;8:e57963.

37. Graversen C, Olesen SS, Olesen AE, Steimle K, Farina D, WilderSmith $\mathrm{OH}$, et al. The analgesic effect of pregabalin in patients with chronic pain is reflected by changes in pharmaco-EEG spectral indices. Br J Clin Pharmacol. 2012;73:363-72.

38. Petersen JM, Forsmark CE. Chronic pancreatitis and maldigestion. Semin Gastrointest Dis. 2002;13:191-9.

39. Slaff J, Jacobson D, Tillman CR, Curington C, Toskes P. Proteasespecific suppression of pancreatic exocrine secretion. Gastroenterology. 1984;87:44-52.

40. Isaksson G, Ihse I. Pain reduction by an oral pancreatic enzyme preparation in chronic pancreatitis. Dig Dis Sci. 1983;28:97-102.

41. Halgreen H, Pedersen NT, Worning H. Symptomatic effect of pancreatic enzyme therapy in patients with chronic pancreatitis. Scand J Gastroenterol. 1986;21:104-8.

42. Malesci A, Gaia E, Fioretta A, Bocchia P, Ciravegna G, Cantor P, et al. No effect of long-term treatment with pancreatic extract on recurrent abdominal pain in patients with chronic pancreatitis. Scand J Gastroenterol. 1995;30:392-8.

43. Mossner J, Secknus R, Meyer J, Niederau C, Adler G. Treatment of pain with pancreatic extracts in chronic pancreatitis: results of a prospective placebo-controlled multicenter trial. Digestion. 1992;53:54-66.

44. Winstead NS, Wilcox CM. Clinical trials of pancreatic enzyme replacement for painful chronic pancreatitis-a review. Pancreatology. 2009;9:344-50.
45. Zubarik R, Ganguly E. The rosemont criteria can predict the pain response to pancreatic enzyme supplementation in patients with suspected chronic pancreatitis undergoing endoscopic ultrasoun. Gut Liver. 2011;5:521-6.

46. Braganza JM. A framework for the aetiogenesis of chronic pancreatitis. Digestion. 1998;59 Suppl 4:1-12.

47. Bhardwaj P, Garg PK, Maulik SK, Saraya A, Tandon RK, Acharya SK. A randomized controlled trial of antioxidant supplementation for pain relief in patients with chronic pancreatitis. Gastroenterology. 2009;136:149-59 e2.

48. Siriwardena AK, Mason JM, Sheen AJ, Makin AJ, Shah NS. Antioxidant therapy does not reduce pain in patients with chronic pancreatitis: the ANTICIPATE study. Gastroenterology. 2012;143:655-63 e1

49. Uden S, Bilton D, Nathan L, Hunt LP, Main C, Braganza JM. Antioxidant therapy for recurrent pancreatitis: placebo-controlled trial. Aliment Pharmacol Ther. 1990;4:357-71.

50. Kirk GR, White JS, McKie L, Stevenson M, Young I, Clements WD, et al. Combined antioxidant therapy reduces pain and improves quality of life in chronic pancreatitis. J Gastrointest Surg. 2006;10:499-503.

51. Dhingra R, Singh N, Sachdev V, Upadhyay AD, Saraya A. Effect of antioxidant supplementation on surrogate markers of fibrosis in chronic pancreatitis: a randomized, placebo-controlled trial. Pancreas. 2013;42:589-95.

52. Cai GH, Huang J, Zhao Y, Chen J, Wu HH, Dong YL, et al. Antioxidant therapy for pain relief in patients with chronic pancreatitis: systematic review and meta-analysis. Pain Physician. 2013; 16:521-32.

53. Durgaprasad S, Pai CG, Vasanthkumar, Alvres JF, Namitha S. A pilot study of the antioxidant effect of curcumin in tropical pancreatitis. Indian J Med Res. 2005;122:315-8.

54. Banks PA, Hughes M, Ferrante M, Noordhoek EC, Ramagopal V, Slivka A. Does allopurinol reduce pain of chronic pancreatitis? Int J Pancreatol. 1997;22:171-6.

55. Salim AS. Role of oxygen-derived free radical scavengers in the treatment of recurrent pain produced by chronic pancreatitis. A new approach. Arch Surg. 1991;126:1109-14.

56. Malfertheiner P, Mayer D, Schiefer B, Buchler M, Ditschuneit H. Does inhibition of pancreatic secretion alleviate chronic pain in chronic pancreatitis? Gastroenterology. 1992;102:A277.

57. Schmalz MJ, Soergel KH, Johanson JF. The effect of octreotide acetate, (sandostatin), on the pain of chronic pancreatitis. Gastroenterology. 1992;102:A290.

58. Lieb JG, 2nd, Shuster JJ, Theriaque D, Curington C, Cintron M, Toskes PP. A pilot study of Octreotide LAR vs. octreotide tid for pain and quality of life in chronic pancreatitis. JOP. 2009;10:518-22.

59. Ballegaard S, Christophersen SJ, Dawids SG, Hesse J, Olsen NV. Acupuncture and transcutaneous electric nerve stimulation in the treatment of pain associated with chronic pancreatitis. A randomized study. Scand J Gastroenterol. 1985;20:1249-54.

60. Vergani F, Boukas A, Mukerji N, Nanavati N, Nicholson C, Jenkins A. Spinal cord stimulation for visceral pain related to chronic pancreatitis: report of 2 cases. World Neurosurg. 2014;81:651 e17-9.

61. Kapural L, Cywinski JB, Sparks DA. Spinal cord stimulation for visceral pain from chronic pancreatitis. Neuromodulation. 2011;14:423-6.

62. Sareen S, Kumari V. Yoga for rehabilitation in chronic pancreatitis. Gut. 2006;55:1051. 